\title{
Qualitative Comparative Study of Frozen Section with Routine Histological Technique
}

\section{ABSTRACT}

Introduction: Intraoperative consultation by frozen section technique is an invaluable tool for immediate diagnosis. Its accuracy and limitations vary with different anatomical sites. Various studies comparing diagnostic accuracy are reported, however morphological quality of frozen section and its limitations have not been widely discussed.

Aim: Qualitative morphological comparison between frozen section and routine formalin fixed paraffin embedded sections in different tissues, determine the diagnostic accuracy and study limitations of frozen section.

Materials and Methods: 67 tissue specimens from 52 cases were studied over a period of 2 years. Diagnostic accuracy of frozen section and its morphological quality and reliability in comparison to histopathology was evaluated by 2 pathologists in a blinded fashion for the following parameters: cellular outline, nuclear and cytoplasmic features, staining pattern and overall morphology. The turnaround time and limitations in section preparation and problems encountered were assessed.

Results: Diagnostic accuracy of frozen section was $96.2 \%$. Statistical analysis showed that nuclear details, cellular outline and overall morphological quality of frozen section was slightly inferior to that of routine histopathology section, however, staining and cytoplasmic details were comparable. Most common limitation was freezing artifact. The average turnaround time was within 20 minutes in $76.9 \%$ cases.

Conclusion: Frozen section is a reliable and accurate intra-operative consultation modality, but one needs to be aware of its indications and limitations. Avoiding technical errors in sectioning and staining, combination of knowledge about clinical presentation and experience in interpretation of morphological details can provide rapid diagnosis and subsequent patient management.

\section{INTRODUCTION}

Frozen section technique was first used by William $\mathrm{H}$ Welch from John Hopkins Hospital in 1891 for intra-operative consultation. It was further developed by Wilson and McCarty in 1905 at Mayo Clinic. This practice has since then evolved especially after development of cryostat in 1959 [1,2]

Intraoperative consultation guides immediate surgical management to establish nature and type of lesion, confirm presence of malignancy, status of surgical margins and ensuring sufficient sampling of lesional tissue. The indications and limitations of frozen section diagnosis vary in different organs. Diagnostic discrepancies between frozen and permanent section are commonly observed in tissue from skin, breast, uterine cervix and thyroid [3-6]

Errors can be divided into errors of interpretation and errors of sampling. These include the initial selection of tissue by the surgeon, the sampling of the tissue by the pathologist, the technical expertise required to prepare the slides, errors in interpretation and delivery of the result back to the surgeons [5,7]. Diagnosis should be deferred when situation warrants [8]. Many published studies have confirmed the overall diagnostic accuracy of frozen section examination and serves as an integral part of quality assurance [9]

Studies comparing the morphological quality of frozen section and formalin fixed paraffin embedded tissue sections have not been widely reported in literature. Also, as frozen section is subject to various pitfalls, this study aims to highlight the qualitative morphological comparison between both the techniques, to establish diagnostic accuracy and determine various limitations of frozen section.

\section{MATERIALS AND METHODS}

This was a prospective study conducted over a period of two years (September 2013 to August 2015) on 67 tissue specimens from 52 consecutive cases received from Surgical Departments for intra-operative consultation. Fresh tissue was sent in a clean plastic container without any fixative or 
saline (to avoid fixation artifacts / degenerative changes) along with requisition form with complete clinical details from the operation theater. Indication of frozen section was recorded. Cases in which only a tiny biopsy was obtained during surgical procedure were deferred from frozen sectioning and processed by routine FFPE technique.

For frozen section: Gross examination was done, specimen dissected and sections were taken from representative areas. Frozen sectioning was done on cryostat (MICROM cryostat HM 525) [Table/Fig-1]. OCT compound (CRYOMATRIX, thermo scientific) was the freezing medium used and was poured onto the chucks. Sections were placed on the still liquid freezing medium. When the medium and tissue were frozen, the chuck was inserted into the clamping lever and was fixed. The ideal temperature for cutting Cryostat sections varied with amount of matrix and lipid content of the tissue. The cryostat was set at a range between $-18^{\circ} \mathrm{C}$ to $-24^{\circ} \mathrm{C}$ depending upon the nature of the tissue. (Lymph node, thyroid, kidney were cut at higher temperature range compared to tissues with more adipose tissue like breast and omentum which required lower temperature, remaining tissues were cut between $-20^{\circ} \mathrm{C}$ to $-22^{\circ} \mathrm{C}$ ). Freezed tissue was initially placed on back freezing rails and gradually moved to Peltier element (4 rapid freezing rails) to avoid rapid freezing and subsequent artifacts. Clearance angle was set at $10^{\circ}$. Sections were cut at a thickness of $4-5 \mu$ and were immediately fixed in 95\% isopropyl alcohol. Rapid hematoxylin and eosin (H\&E) staining was performed. Frozen section diagnosis was made by consensus of 2 pathologists, including one senior pathologist in correlation with appropriate clinical details. It was immediately conveyed to the operating surgeon through intercom. Clinical-frozen diagnosis concordance was analyzed. The turnaround time of entire procedure from receipt of specimen to delivery of report was recorded.

\section{For routine formalin fixed paraffin embedding (FFPE)}

tissue processing: The remaining tissue from FS/specimen received for histopathology was fixed in $10 \%$ buffered formalin. Grossing was done and sections were taken from representative areas. Conventional histoprocessing was performed in automated tissue processor Shandon Citadel 2000. The paraffin embedded sections were cut at 4 to 5 micron and were stained by routine H\&E staining technique in Automatic Thermo Scientific Varistain Gemini ES.

Slides of both frozen and routinely processed sections were compared by two pathologists in a blinded fashion for qualitative assessment of morphological details in terms of cellular outline, nuclear and cytoplasmic features, staining pattern and overall morphology. Each of the five parameters were given a score ranging from 1 to 5 (1= poor), ( 2 = fair), ( $3=$ good), (4= excellent), (5= outstanding). Grading was done by adding the score of each parameter. 5-10 = Poor; 11-15= Fair; 16-20 = Good; 21-25 = Excellent; $>25$ = Outstanding [10]. If there was a discrepancy in assessment of parameters between first two pathologists, such that category of final grade was different, opinion of third pathologist was taken. Two similar scores were considered for final calculation. Scores of two pathologists with close grade were added and average value was taken. Data management and Statistical analysis was performed using SPSS software version 21.0. Chi square test was used. The $p$-value $<0.05$ was considered statistically significant. Frozen section and routine histopathology diagnoses were compared to assess the diagnostic accuracy. The test results were categorized into concordant and discordant groups, the latter was subdivided into false positive and false negative. Indications, turnaround time and limitations of frozen sectioning were also observed.

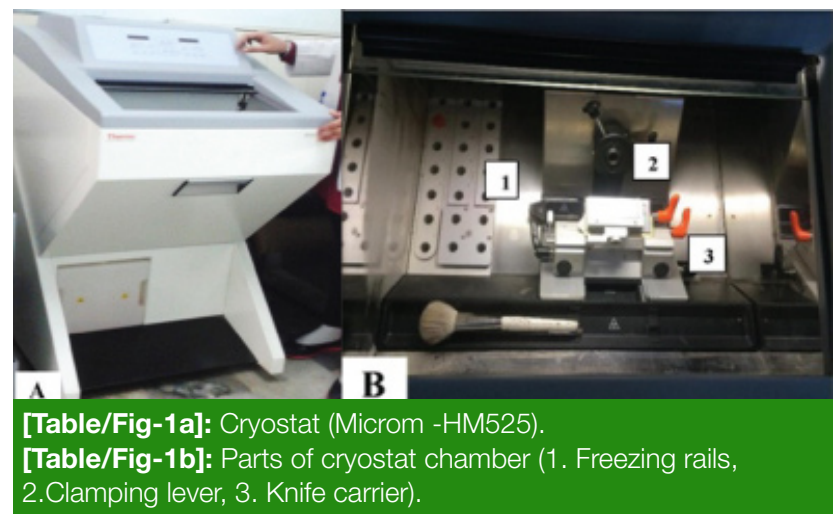

\section{RESULTS}

Frozen section was performed on 67 tissues from 52 consecutive cases, and its diagnosis was compared with final conventional histopathology diagnosis in terms of qualitative morphology, diagnostic accuracy and limitations. Clinicalfrozen section diagnosis was concordant in 50\% cases. While diagnostic accuracy of frozen section was $96.2 \%$ (50/52 cases) when compared with permanent section, two cases were discordant with false negative diagnoses. None of the cases was reported false positive [Table/Fig-2].

The primary indication was presence/typing of neoplasm in 44 cases (54 tissues), clearance of margins in 7 cases (10 margins) and to determine presence of ganglion cells in one case (3 tissues) of Hirschsprung's disease [Table/Fig-3].

Ovary was the commonest tissue received for FS with 18 specimens from 13 cases, all were for presence/typing of neoplasm, clinical-frozen concordance was 25\%. All cases showed diagnostic concordance among frozen and conventional histopathology [Table/Fig-4]. 


\begin{tabular}{|c|c|c|c|c|c|}
\hline S. N. & Tissue processed & No. of cases & No. of tissue & Concordant & Discordant \\
\hline 1. & Ovarian tissue & 13 & 18 & 13 & 00 \\
\hline 2. & Breast tissue & 07 & $08^{*}$ & 07 & 00 \\
\hline 3. & Retroperitoneal organs & 07 & 07 & 07 & 00 \\
\hline 4. & Gall bladder/biliary tract & 06 & 06 & 05 & 01 \\
\hline 5. & Oral cavity & 03 & $06+$ & 03 & 00 \\
\hline 6. & Peritoneal tissue & 03 & $06 \ddagger$ & 03 & 00 \\
\hline 7. & Intestine & 03 & $05 \S$ & 03 & 00 \\
\hline 8. & Thyroid & 03 & 03 & 02 & 01 \\
\hline 9. & Male genital system & 02 & 02 & 02 & 00 \\
\hline 10. & Lymph node & - & $01 \|$ & - & - \\
\hline 11. & Spinal tissue & 01 & 01 & 01 & 00 \\
\hline 12. & Brain tissue & 01 & 01 & 01 & 00 \\
\hline 13. & Soft tissue-back & 01 & 01 & 01 & 00 \\
\hline 14. & Uterus & 01 & 01 & 01 & 00 \\
\hline \multirow[t]{2}{*}{15.} & Parotid gland & 01 & 01 & 01 & 00 \\
\hline & TOTAL & 52 & 67 & 50 (96.2\%) & $2(3.8 \%)$ \\
\hline
\end{tabular}

[Table/Fig-2]: Comparative diagnostic accuracy analysis of frozen with permanent sections $\left\{{ }^{\star} T\right.$ Two and tfour tissues for margin assessment in one case of breast carcinoma and oral cavity malignancy. $¥$ Three peritoneal tissues with ovary. $\S$ Three biopsies in Hirschsprung disease. Peri-pancreatic lymph nodes with gall bladder\}.

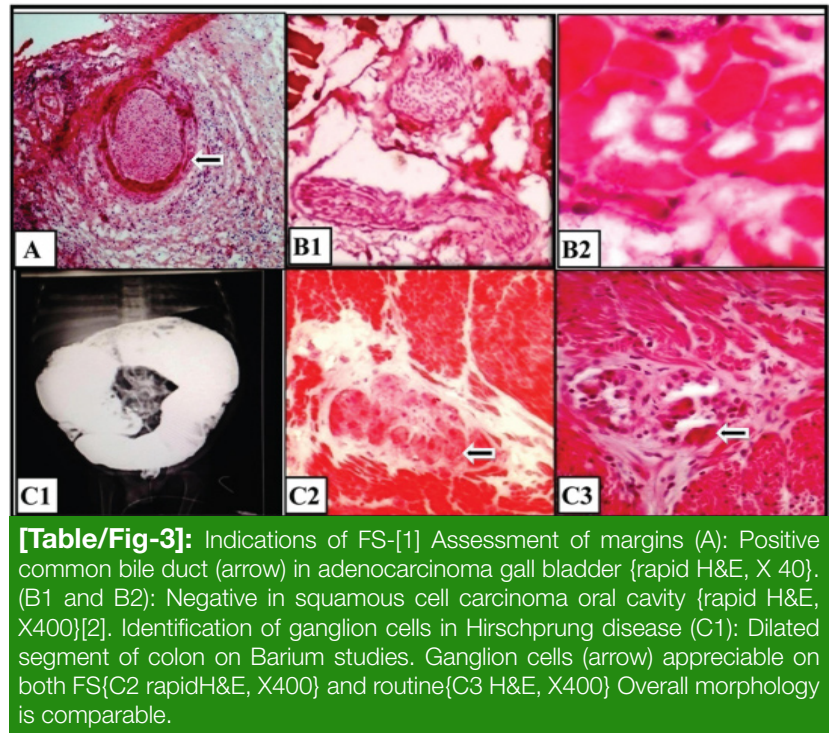

Out of the three thyroid tissues that were sent for presence/ typing of neoplasm, frozen section diagnosis showed discordance with paraffin section in one case which was diagnosed on frozen as hyperplastic change in goiter but final histopathological diagnosis was follicular variant of papillary carcinoma [Table/Fig-5].

Amongst gall bladder specimens, diagnostic discordance was observed in one case. Part of gall bladder with peripancreatic lymph node resection was received. On FS no suspicious or atypical cells were observed in gall bladder and lymph nodes were negative for malignancy. On routine

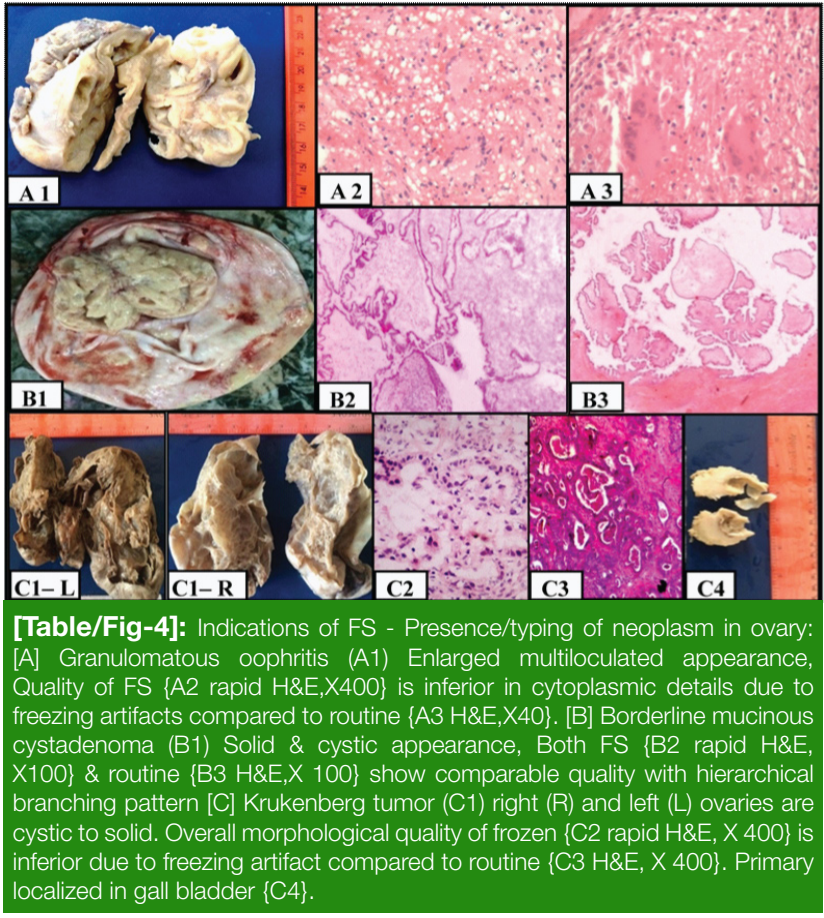

histopathology, remaining tissue from frozen section showed tiny foci suspicious of malignancy and resected gallbladder showed features consistent with adenocarcinoma. Due to the problem observed in this case, later when a similar type of case with inadequate tissue was encountered with thickened wall and occasional suspicious cells, surgeon was requested to send entire cholecystectomy specimen, 


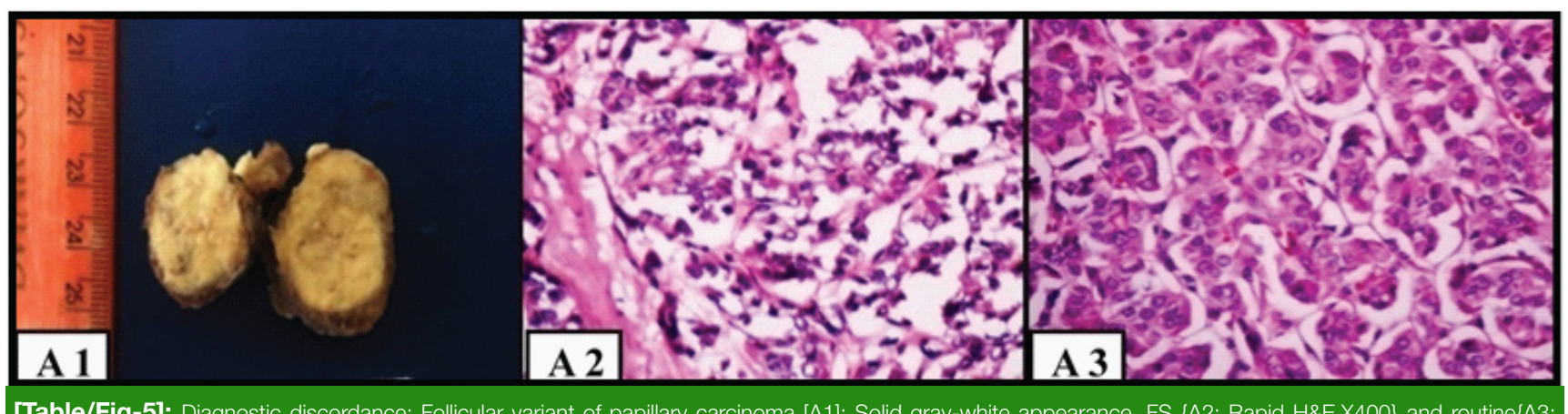

[Table/Fig-5]: Diagnostic discordance: Follicular variant of papillary carcinoma [A1]: Solid gray-white appearance. FS \{A2; Rapid H\&E,X400\} and routine\{A3; $\mathrm{H} \& \mathrm{E}, \mathrm{X} 400\}$ are not comparable due to shrinkage artifact, lack of appreciable nuclear details and follicular pattern.

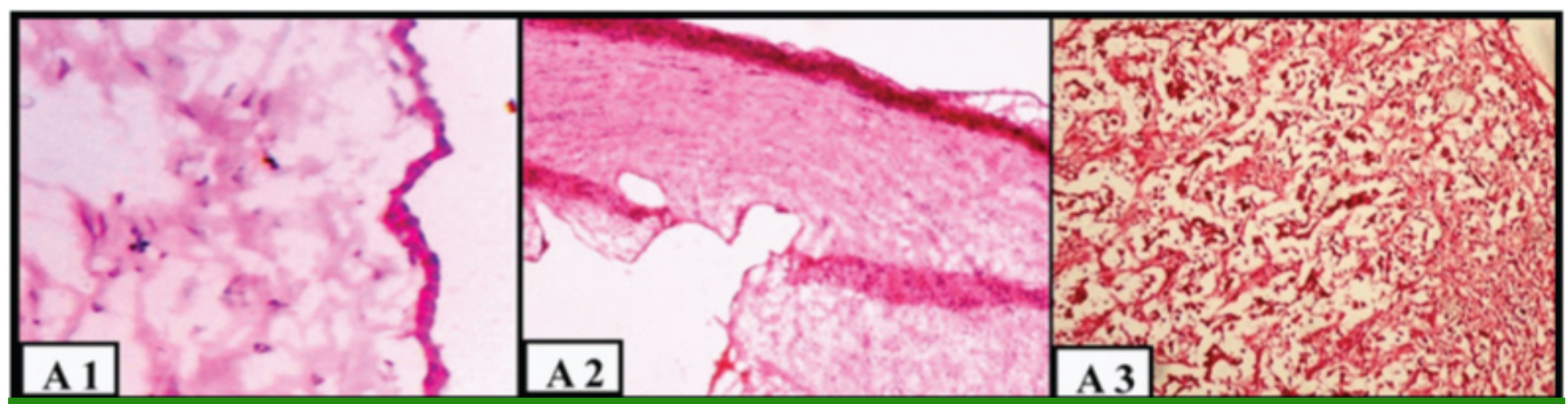

[Table/Fig-6]: Limitations of FS- Freezing (A1) \& sectioning artifact (A2) in benign surface epithelial tumor of ovary \{Rapid H\&E, X40\}. (A3) Shrinkage and freezing artifact in ductal carcinoma of breast \{Rapid H\&E, X40\}.

though the turnaround time exceeded 20 minutes, frozen was indicative of adenocarcinoma.

Thus frozen section discrepancy was attributed to misinterpretation error (1.92\%) and sampling error (1.92\%) in one case each leading to change in diagnostic category. Additional, limitations observed in these cases was lack of adequate clinical details (3.84\%). Technical limitation $(23.07 \%)$ resulted mostly from freezing procedure, obscured nuclear details, shrinkage artifacts followed by sectioning [Table/Fig-6].

As this was a prospective study, diagnosis given at the time of intraoperative consultation was considered as final frozen diagnosis. This was later compared with the histopathological diagnosis. However, intraobserver variability in frozen section diagnosis was not observed when slides were reviewed again during qualitative assessment of morphological features. 2 cases showed diagnostic discordance. Inter- observer variability was observed in scoring for qualitative parameters between 2 pathologists in two cases, one each from brain and spinal tissue. The variability in scoring in these cases was due to presence of necrotic tissue in brain, and keratinous material in cyst from spinal region. Here consensus findings with $3^{\text {rd }}$ pathologist were considered for analyses.

The cellular outline, nuclear details owing to clearing artifact and overall morphology of frozen section was inferior to that of routine section with $p$-value of $0.002,0.03$ and 0.01

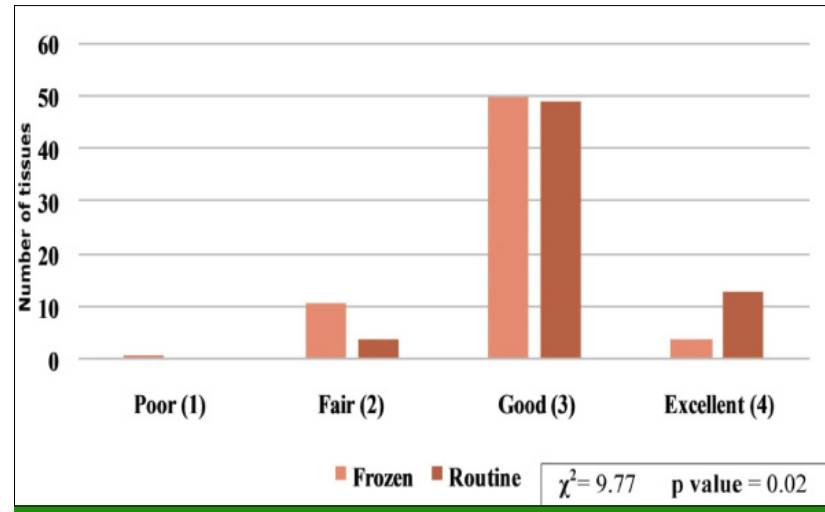

[Table/Fig-7]: Bar graph showing qualitative histologic grade of frozen sectioning in comparison with routine histopathology.

respectively which were statistically significant. The overall staining and cytoplasmic details of frozen section were comparable to that of routine section with $p$-value of 0.08 and 0.06 respectively which is not significant [Table/Fig-7].

Turnaround time was within 20 minutes of receipt of specimen in 40 cases. In 10 cases it was between 20-25 minutes which was due to the large size of the specimen as adequate sampling required thorough inspection of the tissue. In two cases viz. Hirschsprung's disease and suspicion of malignancy due to thickened gall bladder wall, the time exceeded 25 minutes as in both cases repeat request was made to send more tissue. 
Frozen sectioning is a multistep process involving surgical resection, intraoperative preparation of slides and their microscopic examination, communicating FS diagnoses to surgeon and processing the remaining tissue for further workup. Errors may occur due to problems in any of the steps [11]. Quality of prepared sections during cryostat sectioning plays an important role in FS diagnoses. Technical issues leading to alteration in cytological or architectural features necessary for establishing accurate diagnoses during processing of frozen sectioning may pose difficulty. However, use of frozen section with limitations in mind make it a highly sensitive and specific technique playing critical role in management of patients [12]. study was to determine presence/typing of neoplasm to margins (13.5\%) which was also seen in other studies done $[8,11,13,14]$ [Table/Fig-8].

Presence/typing of neoplasms is important to operating surgeon, as this will decide the type of operative procedure or further sampling. Also, margin clearance of a malignant

\section{DISCUSSION}

The most common indication for frozen section in the present rule out malignancy (84.6\%) followed by assessment of

lesion is crucial as tumor recurrence can be aggressive and difficult to treat [15].

Intestinal biopsy from 18 month old boy with Hirschsprung disease (HD) was sent for identification of ganglion cells to decide the level of resection. Distal segment of transverse colon showed paucity of ganglion cell, so more tissue from representative areas were asked, subsequently tissue sent from appendix and proximal segment of transverse colon showed adequate number of ganglion cells. Concordant findings were observed on frozen biopsy block. Diagnosis of $\mathrm{HD}$ is dependent on correct identification of ganglion cells. However, sampling from transition zone, freezing artifacts and inexperience may cause misclassification of other cell types as ganglion cells or failure to recognize them may lead to unnecessary surgeries [16].

The accuracy of frozen section varies in different studies [Table/Fig-9]. Most common cause of discordance of results is false-negative diagnoses, as was observed in present study. The literature reports discordance rates ranging from $1.4 \%$ to $12.9 \%$ in different anatomical sites $[2,3,17]$.

Interpretation error due to the lack of diagnostic morphological features was the cause of discordant diagnosis in one case

\begin{tabular}{|l|c|c|c|c|}
\hline \multirow{2}{*}{ Authors } & \multicolumn{3}{|c|}{ Indications } \\
\cline { 2 - 5 } & Presence / typing of neoplasm & Assessment of margins & Identification of cell & Assessment of nodal status \\
\hline Patil P et al., [8] & $55 \%$ & $34 \%$ & - & $11 \%$ \\
\hline Roy S et al., [11] & $65.9 \%$ & $30.6 \%$ & - & $3.8 \%$ \\
\hline Chbani L et al., [13] & $85.4 \%$ & $7.3 \%$ & $4.3 \%$ & - \\
\hline White V et al., [14] & $41 \%$ & $26 \%$ & - & $28 \%$ \\
\hline Present study & $84.6 \%$ & $13.5 \%$ & $1.9 \%$ & - \\
\hline
\end{tabular}

\begin{tabular}{|l|c|c|c|c|}
\hline Authors & Study Period (year) & Number of Cases & Concordance Rate \% & Discordance Rate $\%$ \\
\hline Shrestha S et al., [1] & 5 & 404 & 94.6 & 5.4 \\
\hline Patil P et al., [8] & 2 & 100 & 96.9 & 3.1 \\
\hline Ahmad Z et al., [9] & 1 & 342 & 97.1 & 2.9 \\
\hline Roy S et al., [11] & 9 months & 327 & 97.6 & 2.4 \\
\hline Chbani et al., [13] & 1 & 261 & 95 & 5 \\
\hline Present Study & 2 & 52 & 96.2 & 3.8 \\
\hline
\end{tabular}

[Table/Fig-9]: Literature overview on frozen section diagnostic accuracy.

\begin{tabular}{|l|c|c|c|c|c|}
\hline \multirow{2}{*}{ Authors } & \multirow{2}{*}{$\begin{array}{c}\text { No. of } \\
\text { cases }\end{array}$} & \multicolumn{5}{|c|}{ Limitations } \\
\cline { 3 - 6 } & & Technical errors (\%) & Sampling errors (\%) & Interpretation errors/ (\%) & Lack of clinical details (\%) \\
\hline Mahe E et al., [3] & $17 / 812$ & 0.12 & 0.6 & 1.5 & - \\
\hline Evans CA et al., [7] & $3 / 240$ & - & 0.4 & 0.8 & \\
\hline Patil P et al., [8] & $3 / 100$ & - & 1.0 & 2.0 & - \\
\hline Present study & $12^{\star} / 52$ & 23.07 & 1.92 & 1.92 & 3.84 \\
\hline
\end{tabular}

[Table/Fig-10]: Different Studies illustrating limitations observed during FS ( ${ }^{*}$ technical artifacts and lack of clinical details was common in one case each with sampling and interpretative error). 
of follicular variant of papillary carcinoma. Freezing artifact is more pervasive in thyroid sections with increased colloid, or blood. Therefore, interpretation of classical ground glass appearance of the nuclei was misinterpretated as a fixation artifact, also papillary structures were not be seen. Frozen section evaluation of thyroid lesion may sometimes be challenging and has limited utility and has caused the greatest number of diagnostic disagreements, largely related to presence/typing of a neoplasm [18].

Proper orientation of specimen and clinical details are important to make an accurate diagnosis. In one case of part of gall bladder specimen diagnostic discordance was observed due to lack of relevant clinical details, also the frozen block had missed the lesion owing to insufficient serial sectioning. A clear, concise and skillful communication pertaining to clinical details may influence the complexity of the case and hence the FS diagnosis. Sampling error is an issue, as a significant proportion of the gallbladder mucosa may be involved but to different extents in different areas in the cholecystectomy specimen $[11,19]$.

Intraoperative diagnosis of the status of malignancy of ovarian tumors by frozen section is important in determining the extent of surgery in young women who desires fertility conservation by preserving contralateral ovary, in diagnosis of borderline tumors and certain cases of endometriosis which are hard to differentiate from malignancy clinicoradiologically $[20,21]$.

In the present study, diagnostic accuracy for ovarian lesions was $100 \%$. It was found comparable with study done by Abdelgehany A et al., [20]. However, in other studies accuracy is low due to the under diagnoses of the borderline and malignant cases [22]. $7 \%$ of ovarian tumors represent metastases from primary neoplasms from other organs. Differentiating these from primary ovarian cancer is necessary for optimal intraoperative management [20]. Metastatic adenocarcinoma (krukenberg tumor) was diagnosis in one case of bilateral ovarian mass, this led the surgeon to look for primary which was found in Gall bladder thus preventing second surgery and further work up to localize primary. Also, two cases clinico-radiologically mimicking malignancy were diagnosed as granulomatous oophoritis on FS. This finding is not widely reported in literature, however as pelvic tuberculosis is common in India it should be among the differential diagnosis of malignancy as it would avoid unnecessary surgery [23].

Tissues from other organs showed diagnostic concordance, though variations in morphological quality were observed when compared with routine sections. This was attributed mostly to technical artifacts.

Many studies [Table/Fig-10] have concluded that disagreements in FS diagnosis are mostly due to interpretative and sampling errors, followed by sectioning, inadequate history, staining and labeling [9]. Most frequent limitation observed in present study were technical errors followed by sampling errors. Similar findings have been observed in other studies $[3,7,8]$. Interpretational errors resulting from technical artifacts like freezing procedure or sectioning are avoidable and can be overcome by experience of the pathologist [24]. An important technical factor causing difficulty in interpretation is quality of section which limits the evaluation of cellular details. This factor is underemphasized in most available studies [20,21]. In the present study we observed that cellular outline and nuclear details were not well delineated especially in inflamed, edematous and fatty tissues, while were well preserved in solid tissues. Due to this the overall morphology and histological quality of FS was inferior when compared to routine section.

CAP specifies that TAT in frozen section reporting should be completed within 20 minutes in $90 \%$ or else analysis of outliers should be done. However, TAT does not include transport time prior to receipt of specimen, and also this standard allows exclusion of cases where multiple sequential studies were performed [25]. The average turnaround time in the present study was 20 minutes with $76.9 \%$ cases reported within 20 minutes or less and was comparable with other studies [5,8,9]. In $19.2 \%$ cases TAT was between 20-25 minutes where multiple sections had to be taken and in $3.8 \%$ cases $>25$ minutes where more tissue was requested.

\section{CONCLUSION}

Frozen section is subject to various limitations which both surgeon and pathologist should keep in mind when ordering and performing the procedure. Various limitations encountered in our study were error in interpretation due to freezing artifact causing distortion of morphological features which occurs due to variation in freezing temperature and time with different types of tissues, inadequate clinical and operative details and lack of orientation leading to sampling error. Further inflamed, edematous and necrotic tissue adjacent to tumor may cause changes in cellular morphological details. This study highlights the effect of freezing on cellular morphology of various tissues, understanding these limitations of distortion in nuclear details and cellular outline may help in interpretation. However, as the number of different types of tissues was not equal, efficacy of FS in terms of qualitative comparison could not be established. More studies incorporating larger sample size may be done to confirm our findings. Avoiding technical errors in sectioning and staining, combination of knowledge about clinical presentation can reduce the limitations and provide rapid, reliable and cost effective details necessary for rapid diagnosis and on table patient management. 


\section{REFERENCES}

[1] Shrestha S, Lee MC, Dhakal H, Pun CB, Pradhan M, Basyal $\mathrm{R}$ et al. Comparative study of frozen section diagnoses with histopathology. Postgraduate medical journal of NAMS. 2009;9(2):1-5.

[2] OzdamarSO, Bahadir B, Ekem TE, Kertis G, DoganB, Numanoglu $\mathrm{G}$, et al. Frozen section experience with emphasis on reasons for discordance. Turkish journal of cancer. 2006;36(4):157-61.

[3] Mahe E, Ara S, Bishara M, Kurian A, Tauqir S, Ursani N, et al. Intraoperative pathology consultation : error, cause and impact. Can J Surg. 2013;56(3):13-18.

[4] Coffey D, Kaplan AL, Ramzy Ml. Intraoperative consultation in gynecologic pathology. Arch Pathol Lab Med. 2005; 129(12):1544-57.

[5] Hull ME, Humphrey PA, Pfeifer J. Frozen sections and other intraoperative consultations. In: Humprey P, Dehner L, editors. The Washington Manual of Surgical Pathology. $2^{\text {nd }}$ ed. India: Lippincott Williams and Wilkins; 2012.p.832-37.

[6] Rosai J. Introduction. In: Rosai J. editor. Rosai \& Ackerman's Surgical Pathology. 10 ${ }^{\text {th }}$ ed. India: Elsevier; 2011.p.1-12

[7] Evans CA, Suvarna SK. Intraoperative diagnosis using the frozen section technique. J Clin Pathol. 2006; 59(3):334.

[8] Patil P, Shukla S, Bhake A, Hiwale K. Accuracy of frozen section analysis in correlation with surgical pathology diagnosis. Int $J$ Res Med Sci. 2015;3(2):399-404.

[9] Ahmad Z, Barakzai MA, Idrees R, Bhurgri Y. Correlation of intraoperative frozen section consultation with the final diagnosis at a referral center in Karachi, Pakistan. Indian J Pathol Microbiol. 2008;51(4):469-73.

[10] Tripathi M, Bansal R, Gupta M, Bharat V. Comparison of routine fixation of tissues with rapid tissue fixation. Journal of clinical and diagnostic research. 2013;7(12):2768-73.

[11] Roy S, Parwani AV, Dhir R, Yousem SA, Kelly SM, Pantanowitz $\mathrm{L}$. Frozen section diagnosis is there discordance between what pathologists say and what surgeons hear? Am J Clin Pathol. 2013;140:363-69.

[12] Mayun AA, Pindiga UH, Abubakar A. Frozen Section : The need for intra-operative consultation between the surgeon and the pathologist. BOMJ. 2006;3(2):1-2

[13] Chbani L, Mohamed S, Harmouch T, Fatemi HE, Amarti A. Quality assessment of intraoperative frozen sections: an analysis

\section{AUTHOR(S): \\ 1. Dr. Saumya Mishra \\ 2. Dr. Mamta Gupta \\ 3. Dr. Vinay Bharat \\ 4. Dr. Rani Bansal}

\section{PARTICULARS OF CONTRIBUTORS:}

1. Junior Resident, Department of Pathology, Subharti Medical College, Meerut, UP, India.

2. Associate Professor, Department of Pathology, Subharti Medical College, Meerut, UP, India.

3. Professor, Department of Pathology, Subharti Medical College, Meerut, UP, India. of 261 consecutive cases in a resource limited area: Morocco. Health. 2012;4(7):433-35.

[14] White VA, Trotter MJ. Intraoperative consultation / Final diagnosis correlation relationship to tissue type and pathologic process. Arch Pathol Lab Med. 2008;132:29-36.

[15] Jaafar H. Intra-operative frozen section consultation: concepts, applications and limitations. Malaysian Journal of Medical Sciences. 2006;13(1):4-12.

[16] Shayan K, Smith C, Langer JC. Reliability of intraoperative frozen sections in the management of Hirchsprung's disease. 2004;39(9):1345-48.

[17] Da Silva RDP, Souto LRM, Matsushita GDM, Matsushita MDM. Diagnostic accuracy of frozen section tests for surgical diseases. Rev Col Bras Cir. 2011;38(3):149-54.

[18] Anton RC, Thomas M. Wheeler TM. Frozen section of thyroid and parathyroid specimens. Arch Pathol Lab Med. 2005;129:157584.

[19] Lechago J. Frozen section examination of liver, gallbladder, and pancreas. Arch Pathol Lab Med. 2005;129:1610-18.

[20] Abdelghany AM, Arafa EM, Madkour NM, Nossair WS, Mohamed EA, Abdelsalam WA, et al. Accuracy of intraoperative frozen section in the diagnosis of ovarian neoplasms. Open Journal of Obstetrics and Gynecology. 2005; 5:14-22.

[21] Mohammed ABF, Ahuja VK, Farghaly $\mathrm{H}$. Role of frozen section in the intraoperative management of ovarian masses. Middle east fertility society journal. 2015;20:97-101.

[22] Brun J-L, Cortez A, Rouzier R, Callard P, Bazot M, Uzan S, et al. Factors influencing the use and accuracy of frozen section diagnosis of epithelial ovarian tumours. Am J Obstet Gynecol. 2008;199:244.e1-244.e7.

[23] Bharatnur S, Ramkumar V, Kudva R. Abdominopelvic tuberculosis masquerading ovarian malignancy. IJMDS. 2014;3(1):335-38.

[24] Chandramouleeswari K, Yogambal M, Arunalatha P, Bose $\mathrm{JC}$, Rajendran A. Frozen and paraffin sections-Comparative study highlighting the concordance and discordance rates in a tertiary care centre. IOSR Journal of Dental and Medical Sciences.2013;12(5):26-30.

[25] Taxy JB, Husain A, Montag A. The frozen section: Historical background, technique, and quality assurance. In: Montang A. editor. Biopsy interpretation: The frozen section. $2^{\text {nd }}$. Philadelphia: Lippincott Williams \& Wilkins; 2014.p.1-15.

4. Professor and Head, Department of Pathology, Subharti Medical College, Meerut, UP, India.

\section{NAME, ADDRESS, E-MAIL ID OF THE} CORRESPONDING AUTHOR:

Dr. Mamta Gupta,

Associate Professor, Department of Pathology,

Subharti Medical College, Swami Vivekananda Subharti

University, N.H. 58, Meerut, UP, India.

E-mail: drmamtagupta2016@gmail.com

FINANCIAL OR OTHER COMPETING INTERESTS:

None.

Date of Online Ahead of Print: Mar 04, 2016 Date of Publishing: Apr 01, 2016 